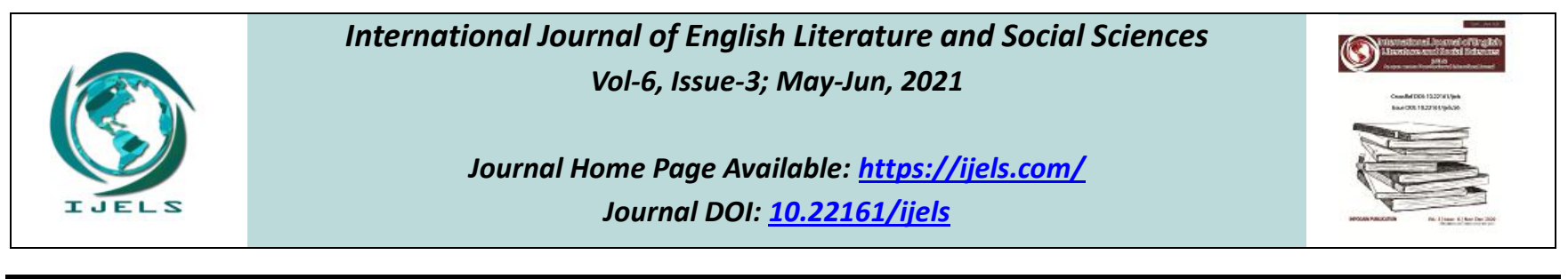

Peer-Reviewed Journal

\title{
A Review of the Impact of Reading "Political Gossips Column in Daily Mirror News Paper" on Improving Vocabulary of the Adult Learners
}

\author{
G.H. Abeyweera
}

Department of English Language Teaching (DELT), Uva Wellassa University of Sri Lanka, Sri Lanka

Received: 11 Feb 2021; Received in revised form: 19 Apr 2021; Accepted: 01 May 2021; Available online: 17 May 2021

(C2021 The Author(s). Published by Infogain Publication. This is an open access article under the CC BY license

(https://creativecommons.org/licenses/by/4.0/).

\begin{abstract}
Reading newspapers plays a significant role in the life of the reader depending on the preference given on the types of article. Although, there are many criticisms in the present context that the trends of the media have been towards financial benefits, some studies focus on the importance of reading newspapers in improving English Language Vocabulary in the target language. Several young researches have been conducted on the impact of reading newspapers, particularly English newspapers in improving vocabulary in the readers. However, the main aim of this paper is to investigate the impact of reading a particular news column named 'political gossips' in improving the English Vocabulary of the adult learners depending on a literature review available in response to myriad articles published in the given newspaper. Despite many researches focuses on the impact of reading newspapers on different aspects of language learning, this conceptual paper attempts to shed some light on the benefits of reading newspapers particularly a selected news column and the challenges which adult learners face in comprehending and using the vocabulary picked up in reading. The findings of this study show that reading the given column in the newspaper not only improve the vocabulary of the adult learners but more importantly article challenges in comprehending and using them in a given context. In addition, the findings shows that there are advantages as well as disadvantages in reading the news column in improving the vocabulary.
\end{abstract}

Keywords-analyses, benefits, impact, newspapers, vocabulary.

\section{INTRODUCTION}

In the present context, there is an increasing trend towards reading newspapers either on print or electronic version in getting to know the news happening around the world. In the recent context the trends in reading are more towards health and the political outbreaks rather than any other facet. Reading newspapers are manifold. Reading newspapers are mainly for gathering news happening around the world. In addition, newspapers are also used for entertainment, reading for pleasure, advertisements, giving publicity for events etc. Amongst news items in a given paper. Some articles focus on communicating real occurrence particularly in the political arena but unable to articulate directly impending dangers of such writing. In such instances, indirect communication is made with sarcasm, at times with ironical statements using interesting vocabulary. As the news articles specifically stated carry humorous, witty, sarcastic and ironic remarks along with suspension, the reader of such news articles is attracted to them for they simulate the interest of reading them. Thus, this review is significant as it attempts to portray the impact of reading a selected news column over a period of year in enhancing the vocabulary of the adult learners. 


\section{REVIEWING SOME RELEVANT LITERATURE}

Newspapers are pieces of materials providing updated news and knowledge of all the latest incidents and events taking place around the globe. Albeit, the history of newspapers dates back to the $17^{\text {th }}$ century, they have become an in-separable element of the lives of people in the world. Thus, being a good reader, reading will have a greater impact in it as it assists one to reach excellence of knowledge. As the saying goes, if someone learns to read then he will read to learn irrespective of differences. In this way, reading opens door to culture, knowledge and independence which is true as the information contains in newspapers have tremendous impact on perception, acculturation and transformation of individuals. By means of reading newspapers knowledge of the individual is enhanced, intellect and critical thinking is sharpened and misconceptions fade-away (Nkiko \& Yusuff, 2006).

According to Braunger and Lewis (2006), reading enlightens the mind, make the intellect sharper and makes an individual travel across the globe without motion. It is evident that reading changes the habits and patterns of behavior of individuals when it becomes a habit which is highly rewarding as it makes individual knowledgable, well-informed and well-reserved about the news happening in the globe. On the other hand, newspapers are the most accessible and available written information for people of all categories irrespective of boundaries (Babalola,2002). Gbadamosi (2007) emphasizes that reading culture in essence a kind of culture that imbibes reading and studying as the basis of growth and development. In line with this statement, it is reading by individuals: young, old, students, adults and many more for knowledge acquisition causing for enhancing knowledge.

Reviewing about the significance of reading newspapers, Kanizmoun (2013) commented that the world becomes smaller and smaller with the advancement of media which includes all types including newspapers which can carry information to a large amount of people in the world. It provides latest news about the world scenario playing a salient role in the field of media. Olorunsola (1997) asserted that reading newspapers can help to mould the whole man as reading newspapers tremendously increase and enhance the learning by which vocabulary and knowledge creation, development and spelling ability are enhanced.

From all the relevant few though reveal the fact that reading newspapers play a pivotal role in developing, enhancing and in overall moulding the whole man and it is worthwhile in reviewing the impact of reading newspapers with particular reference to improving the vocabulary of the adult learners.

\section{Objectives}

1. To identify the advantages of reading newspapers in general

2. To determine to what extent the particular news column is read by adult learners

3. To analyze the sentence structure of selected sentences of selected news column

4. To provide a review of the use of vocabulary and its richness in the given column

\section{METHODOLOGY}

To do this descriptive content analysis was adopted for this review and a collection of headlines appeared in the 'Political Gossip' column was randomly selected as the sole primary data. The search of different articles was limited to a single newspaper named Ceylon Dailymirror in which the news column 'political gossip' which included 72 articles (06 articles per month into 12 months) was taken for analysis.

\section{DISCUSSION}

It is noteworthy in finding out some of the central advantages in reading newspapers. Among many, strengthening reading and writing skills of learners both young and adult, providing entertainment and news about famous sports, creating platforms for a best source of knowledge, to be well-informed or being up-to-date with politics, gathering useful ideas about researches and projects, improving vocabulary skills of the reader and, making them good speaker are some of the indispensable advantages among too many.

Improving and enhancing vocabulary of the reader ought to be given greater emphasis as in many newspapers, there is a separate page where readers find useful as well as enjoyable games like sudoku, puzzles, riddles and tonguetwisters as mind games which help to improve and enhance the vocabulary of the reader in general. Thus, daily reading of newspapers enhances the vocabulary and the skills of learners as they learn different words in creative sentence structures. Learners can jot them down and practice vocabulary skills using the new words learn from papers in different ways to prop-up their meaning. This will ultimately help in writing good essays and assignments in any given social setting. 


\section{Analysis of selected articles from the "Political Gossip" News Column}

Many of these headlines coming under this column are impressive to the reader as they deal with the speculations but true incidents that are taking place in the country, particularly in the context of political administration and development. The themes highlighted in this news also is equally interesting as they often appeal to the heart and mind of the reader. More interesting enough all these articles are carried out with caricatures which cajole the reader to read the articles.

Office has turned into a love nest! is one such article appeared in the given news column. This accompanies a beautiful caricature which truly compels the reader to read and find out what is happening inside the article. This particular news also carries a statement 'If love is blind, infatuation could be worse' they say. It says that this growing love affair was between a white-collar high up and a comely lass which is a story coming down the grapevine. The inquisitive news is that most of the office time is devoted to cooing and necking and they find hardly any time to attend onerous duties. This news paves the way for the reader to think in many perspectives such as one's duty, behavior of the officers, accountability of the government officers, misappropriation of finance and many more while the article carries interesting phrases, words in enhancing vocabulary of the reader. What is remarkable is that most of these articles are read by adult learners and they accumulate these language elements to their interest. Among many interesting elements, office turning into a love nest, infatuation could be worse, a vital state institution, while-collar high up, a comely lass, a story coming down the grapevine, cooing and necking and onerous duties etc. are novel expressions added to the vocabulary of the adult learners.

Moving into another interesting article with descriptive methodology, the readers are taken into another social aspect of corruption. The title 'Beauty Care at Public Expense' draws the attention of the reader to find out where and hos it is taking place. Thus, it makes the reader, particular adult readers curious about searching information. It starts as 'believe it or not! With an exclamation about a lady serving in the foreign service taking beauty care at public expense who penchant for the beauty. It further provides details about the lady as a diplomat who had made several foreign trips under the pretext of seeking eye treatments. Having found the misappropriation of funds, the punishment is to send her as an envoy to the land of Kangaroos: the Australia, hilarious. If some of the novel words and phrases are extracted, public expense, an unusual penchant, well-groomed appearance, bigwig, in the presence of the indulgent political bigwig, to foot a bill running into several millions, under the pretext of, unsavory details, in the highest echelons, a big gun as our envoy etc. are words and phrases which impress the mind of the reader.

The news article 'It would have been a news-making picture!' is another article which awakens minds of the public on an incident that took place in parliament which the author calls 'Diayawannawa'. The news is about a birthday celebration of a member whose symbolic cutting of the cake to celebrate the birthday. The story goes in an interesting manner in which the particular lady' mode of wishing was the eye-catching of everyone present. Many expected she would turn into a more affectionate mode of wishing but she did in the usual way shaking the hand where one senior member told her 'a mere hand-shake in your case will not do'. The news is undoubtedly fascinating while it carries once again a significant number of words and phrases such as, coincide with the voting day, after partaking the piece of cake, affectionate mode of wishing, a mere hand shake won't do, the lady member prompted the birthday celebrant, typical oriental fashion etc. which attract the minds of the reader.

'outsider-couple is a nuisance to them!' is another news article about a couple who moved recently to a bungalow belonging to a statutory body. The drivers of the airport are also residing before the couple moves there and this couple used to take the service of the airport drivers disturbing them at odd times which is the nuisance. Once again, this too provides interesting words and phrases where adults learners acquire them with much enthusiasm. The most highlighted words and phrases taken from this news article are, outsider-couple, pain in the neck, statutory body, purview, odd hours and, never ending nuisance.

The other selected article is "The Seating Arrangement Didn't Suit Him?" which appeared on March 31 2021. When one sees the title of the news article, it appeals to the reader and the reader is cajoled to inquire about the news. It is about a ceremony where both member of parliament were present. Since the Chief Guest had not been given a distinctive place, the Chief Guest had left the function half-way through. This paves the way for the reader to think about the attitudes of the people, attitudes of the politicians, intention of the organizers in many facets etc. while learners are adding words to their vocabulary such as, suburb of city, flanked by, Diyawanna politicos, a certain person faulted the organizer, distinguished guests etc.

'They are lukewarm about the proposed support! Is article that attracts the mind of the reader. The time itself suggests the fact that curiosity is created to find out the details of 
the incident. It gives rooms for the reader to find out about people they speculate in the news. For instance, 'a heavy weight of the green party' makes point for the reader who this Green Party Heavy Weight is? This heavy weight is languishing for something. Why is he/she is languishing about? He is languishing about a State lodge. What is this State lodge about? It is in connection with the bond case? What is this bond case about? Then the reader will guess as is supposed about Bonds Scam. Thus, the news item compels the reader to go on reading until they dig out the whole news. The vocabulary employed in the news also seems interesting. Words such as, heavy weight, lukewarm, in his hour of need, colleague in hot water, Green stalwarts, dragging their feet, wrongdoers, prominent high up from Galle etc. suit the context in creating producing the news.

The next news item is about how petty cash being spent in a government office. The title goes as, 'Hefty Payments from a Petty Cash Imprest!'in which it says a prominent government office in the regime incurring petty expenses alone a day running into about Rs. 2 million. According to the news item, an aide of the political authority receiving the above amount daily on behalf of his boss dutifully accounts for it providing bills in respect of the cash payment. This is surprising such an amount is spent for a day despite other difficulties in the country. This article also enlightens the minds of the reader to think about how public fiancé is spent lavishly not being accountable. Turning into the point of vocabulary, the article provides a group of words and phrases which could be used in other occasions. Some of these are: hefty payment, petty cash imprest, incurring petty cash, an aide of the authority, dutifully accounts, white color high-ups, highly perturbed over this public expenditure, political authorities overridding administrative regulations, under the purview of etc.

\section{CONCLUSION}

It was found that by reading the 'political gossip column' in the particular newspaper will have a greater impact on the improvement of the vocabulary of learners, in this case vocabulary of the adult. Most of these articles are read by the adults who show an interest in reading such speculating yet true news. When analyzing all the randomly selected articles, the number of new words and phrases employed in these writing is remarkable. The adults who used to read these column collects a significant unlimber of words and phrases into their mental lexicon. Thus, from the above analysis, it is evident that reading 'political gossip news column in the given newspaper will have a greater impact on the improvement of the vocabulary of the adult learners.

\section{REFERENCES}

[1] Kin, J.Y. \& Anderson, T. (2011). Reading across the Curriculum: A framework for improving Reading Habits. Journal of Literacy and Reading

[2] Nadler, B.J., Nadler, J., Nadler, J. (2005). Words You Should Know in High School. Adams Media

[3] Epstein, L. (2009). Reading Financial Reports for Dummies. For Dummies

[4] Centre for Educational Research \& Innovation, (2008). Teaching, Learning and Assessment for Adults: Improving Foundation Skills, OECD Publishing

[5] Babalola, E. A. (2002). Newspapers as instruments for building literate communities: The Nigerian experience. Nordic Journal of African Studies 11

[6] Nkiko, C. \& Yusuff, F.O. (2006). Bibliotherapy and Aging among Covenant University Staff. Ife Psychologia

[7] Grishaeva, L. I. \& Tsurikova, L. V. (2004). Introduction to Intercultural Communication: Textbook, (2nd ed.). Voronezh: Voronezh State University

[8] Kupriyanov, I. A. (2008). Reading newspapers in English. MGOPU

[9] Mustaq, J. (2015). Habits and motives of reading newspaper among in Al-Beroni University of Afghanistan. Master thesis, University Malaysia Pahang http://www.dailymirror.lk/ 